\title{
The Long-Term Psychosocial Impact of a Surprise Chemical Weapons Attack on Civilians in Halabja, Iraqi Kurdistan
}

\author{
Jonathan Dworkin, MD, * Marta Prescott, MPH, $\dagger$ Rawan Jamal, Bcs, $\neq$ Soran Ali Hardawan, MD, $\neq$ \\ Aras Abdullah, MD, $\neq$ and Sandro Galea, MD, DrPH†
}

\begin{abstract}
War and human rights abuses contribute to increased prevalence of posttraumatic stress (PTS) disorder and low social functioning among populations affected. There is relatively little evidence, however about the long-term mental health impact of war on general populations. We examined the prevalence of PTS symptoms and poor social functioning in Halabja, Iraqi Kurdistan, 18 years after a chemical attack on civilians in that town. We systematically sampled 291 persons representative of the population of Halabja from the city emergency department and 4 outpatient clinical sites. PTS symptoms and poor social functioning were common. After adjustment for covariates, female gender, older age, and cumulative exposure to multiple traumas, all were associated with higher PTS scores and worse social functioning. Exposure to human rights abuses and warlike conditions seem to continue to be risks for psychiatric and social dysfunction even decades after the initial incident.
\end{abstract}

Key Words: Trauma, mass trauma, PTSD, stress, psychiatric, psychosocial, Harvard Trauma Questionnaire, human rights, chemical, war, Iraq, Kurd, Anfal, Halabja.

(J Nerv Ment Dis 2008;196: 772-775)

raqi forces launched surprise chemical attacks against the Kurdish civilian population of Halabja in March 1988 and these attacks killed 5000 people over the next 2 days (Human Rights Watch, 1991; 1993). Despite media coverage of these attacks and subsequent interest in prosecuting the military and political officers responsible (Burns, 2007), there have been few studies published in the medical literature on the health consequences of these attacks among survivors.

The purpose of our study was to assess the mental health status and general functioning of the civilian popula-

*Internal Medicine Residency Program, University of Hawaii, Honolulu, Hawaii; †Center for Social Epidemiology and Population Health, Department of Epidemiology, University of Michigan School of Public Health, South University, Ann Arbor, Michigan; and †College of Medicine, University of Sulaimania, Sulaimania, Iraq.

Send reprint requests to Sandro Galea, MD, DrPH, Department of Epidemiology, University of Michigan School of Public Health, 1214 South University, Room 243, Ann Arbor, MI 48104-2548. E-mail: sgalea@ umich.edu.

Copyright (C) 2008 by Lippincott Williams \& Wilkins

ISSN: 0022-3018/08/19610-0772

DOI: $10.1097 / \mathrm{NMD} .0 \mathrm{~b} 013 \mathrm{e} 3181878 \mathrm{~b} 69$ tion of Halabja, Iraqi Kurdistan and to determine the persons in this population who were more vulnerable to long-term psychiatric and social impairment eighteen years after the chemical attack on that town.

\section{METHODS}

\section{Sampling}

We recruited a systematic sample of patients who presented to the Halabja City Hospital emergency department, which handles the largest proportion of the city's ambulatory patient traffic, and 4 additional outpatient clinics in Halabja. All 5 sites were administered by the Kurdistan Ministry of Health, and together they constituted the public health infrastructure of the city. Data collection was carried out between January 29th and March 2nd of 2006.

All persons over the age of 26 who presented to any of the research sites during daytime hours were eligible to complete a survey. Younger patients were excluded to ensure that all participants would have been at least 8 years old during the time frame of interest. All interviewers were trained residents of Halabja. All interviews were conducted in Sorani, the Kurdish dialect spoken in the Shahrizur, and were conducted anonymously. The project was reviewed and approved by the Kurdish Ministry of Health, and it received technical and financial assistance from the College of Medicine at the University of Sulaimania in Iraqi Kurdistan.

\section{Survey Measures}

The Harvard Trauma Questionnaire (HTQ) was used to assess posttraumatic stress (PTS) symptoms, self-perception and functioning (SPF), and stressful life events. The HTQ consists of 16 items consistent with DSM-IV PTS symptoms, a separate set of 24 symptoms to assess general functioning, and a question list of 40 stressful life events. The HTQ has been used widely in developing country settings (Mollica et al, 1992). All trauma exposures were categorized into 3 main categories according to the HTQ. The first category was trauma exposures as a result of direct violence such as rape, assault, and torture. The second category was trauma exposures excluding direct violence but considered shocking events (e.g. material deprivation, forced to harm others, witnessed murders, etc.). The third category was trauma exposures that involved violence toward or murder of a family member or close friend. 


\section{Analysis}

Descriptive statistics (i.e., frequencies, means, medians, and distributions) were first examined for all demographics variables, traumatic events, and psychopathology symptoms. The PTS and SPF scores were calculated for each demographic group (e.g., gender, age, education, etc.). The PTS and SPF scores were compared within each demographic category using $t$ tests to examine bivariate associations or the analysis of variance for different age groups.

PTS and SPF scores were calculated for those who did and did not experience a main traumatic exposure and $t$ tests were used to compare the scores for both groups. Multivariable models were created where the sociodemographic correlates of PTS and SPF scores documented in bivariate analyses were used to predict PTS and SPF scores. The PTS and SPF score outcomes were log transformed for normality.

All analyses were run using SAS 9.1.

\section{RESULTS}

Table 1 shows the prevalence in our sample group of known demographic risk factors for PTS disorder. Women had a higher PTS $(p<0.01)$ and SPF $(p=0.05)$ score within the Kurdish population. Older age also was associated with higher PTS $(p<0.01)$ and SPF scores $(p<0.01)$. SPF score was increased in unemployed persons $(p=0.03)$, although there was no association between employment and PTS score.

Table 2 shows the associations between exposure to any of the main event traumas and an increase in PTS and SPF score. Persons who experienced a direct personal trauma had an increase in PTS score $(p=0.05)$ and SPF score $(p<$ 0.01 ), compared with those who did not experience the event. Persons who experienced a direct shocking event also had an

TABLE 1. Demographic Characteristics of Residents of Halabja, Iraq

\begin{tabular}{|c|c|c|c|c|c|}
\hline & & Mean PTS & & Mean SPF & \\
\hline & $N=291$ & Score** & $p$ & Score** & $p$ \\
\hline Gender & & & $<0.01 *$ & & 0.05 \\
\hline Male & 190 & 1.83 & & 1.75 & \\
\hline Female & 101 & 1.97 & & 1.87 & \\
\hline Age & & & $<0.01 *$ & & $<0.01^{\mathrm{a}}$ \\
\hline $26-35$ & 130 & 1.87 & & 1.75 & \\
\hline $36-45$ & 78 & 1.77 & & 1.71 & \\
\hline $46-55$ & 50 & 2.04 & & 1.92 & \\
\hline $56+$ & 33 & 1.92 & & 1.94 & \\
\hline Education & & & 0.09 & & 0.35 \\
\hline$\leq$ High school & 250 & 1.89 & & 1.80 & \\
\hline$>$ High school & 41 & 1.78 & & 1.73 & \\
\hline Currently employed & & & 0.27 & & 0.03 \\
\hline No & 55 & 1.93 & & 1.91 & \\
\hline Yes & 236 & 1.86 & & 1.77 & \\
\hline
\end{tabular}

*Assumption of Variance was violated in the pooled $t$ test and therefore the statterthwaite statistic and $p$ value were used.

**PTS score based on number of symptoms from DSM-IV diagnosis of PTSD, and mean score of Self-perception and functioning scale.

${ }^{a}$ Analysis of Variance, $F$ test.
TABLE 2. Bivariate Associations Between Exposure to Traumatic Event Categories, PTS, and Functioning in a Sample of Residents of Halabja, Iraq

\begin{tabular}{|c|c|c|c|c|c|}
\hline Traumas & $N=291$ & $\begin{array}{l}\text { Mean } \\
\text { PTS } \\
\text { Score }^{\mathrm{a}}\end{array}$ & $p$ & $\begin{array}{l}\text { Mean } \\
\text { SPF } \\
\text { Score }^{\text {a }}\end{array}$ & $p$ \\
\hline $\begin{array}{l}\text { Main event 1: direct event, } \\
\text { assault, or intentional } \\
\text { violence }\end{array}$ & & & 0.05 & & $<0.01$ \\
\hline No & 37 & 1.75 & & 1.55 & \\
\hline Yes & 254 & 1.90 & & 1.83 & \\
\hline $\begin{array}{l}\text { Main event 2: direct shocking } \\
\text { event }\end{array}$ & & & 0.04 & & $<0.01$ \\
\hline No & 4 & 1.45 & & 1.20 & \\
\hline Yes & 287 & 1.88 & & 1.80 & \\
\hline A: Material deprivation & & & 0.58 & & 0.96 \\
\hline No & 47 & 1.85 & & 1.80 & \\
\hline Yes & 244 & 1.88 & & 1.79 & \\
\hline B: Witness violence to others & & & $<0.01$ & & $<0.01$ \\
\hline No & 177 & 1.81 & & 1.72 & \\
\hline Yes & 114 & 1.99 & & 1.91 & \\
\hline $\mathrm{C}$ : Forced to harm others & & & $<0.01$ & & $<0.01$ \\
\hline No & 264 & 1.85 & & 1.77 & \\
\hline Yes & 27 & 2.17 & & 2.04 & \\
\hline $\begin{array}{l}\text { D: Forced confinement and } \\
\text { coercion }\end{array}$ & & & $<0.01$ & & 0.02 \\
\hline No & 22 & 1.59 & & 1.57 & \\
\hline Yes & 269 & 1.90 & & 1.81 & \\
\hline E: Experience dangerous event & & & 0.02 & & $<0.01$ \\
\hline No & 55 & 1.76 & & 1.60 & \\
\hline Yes & 236 & 1.91 & & 1.84 & \\
\hline $\begin{array}{l}\text { Main event 3: disappearance, } \\
\text { death, or injury of } \\
\text { loved ones }\end{array}$ & & & $<0.01$ & & $<0.01$ \\
\hline No & 125 & 1.71 & & 1.63 & \\
\hline Yes & 166 & 2.00 & & 1.92 & \\
\hline
\end{tabular}

a PST score based on number of symptoms from DSM-IV diagnosis of PTSD, and mean score of self-perception and functioning scale.

increase in PTS score $(p=0.04)$ and SPF Score $(p<0.01)$, compared with those who did not. Persons who experienced trauma to a loved one also had increased PTS score ( $p=$ $0.01)$ and SPF score $(p<0.01)$.

Table 3 shows the relation between each exposure and PTS and SPF scores after adjustment for demographic variables. Direct personal trauma was significantly associated with an increased SPF score $(p=0.01)$ but not PTS score. Direct shocking events was significantly associated with the PTS score $(p=0.05)$ and SPF score $(p=0.04)$. Trauma to a loved one was associated with the PTS score $(p<0.01)$ and SPF score $(p<0.01)$.

Figure 1 shows that persons who experienced multiple traumas had an additive increase in their PTS scores.

\section{DISCUSSION}

In a study of a systematic sample of civilian residents of Halabja, Iraqi Kurdistan, conducted 18 years after a military operation directed at the town, we found that Kurds who 
TABLE 3. Multivariate Models Predicting PTS and Self-Perception and Functioning in a Sample of Residents in Halabja, Iraq

\begin{tabular}{|c|c|c|c|c|}
\hline & \multicolumn{2}{|c|}{ PTS Score** } & \multicolumn{2}{|c|}{ SPF Score** } \\
\hline & Beta & $p$ & Beta & $p$ \\
\hline Female & 0.12 & 0.02 & 0.13 & 0.03 \\
\hline \multicolumn{5}{|l|}{ Age* } \\
\hline $36-45$ & -0.10 & 0.06 & -0.06 & 0.33 \\
\hline $46-55$ & 0.14 & 0.03 & 0.14 & 0.06 \\
\hline $56+$ & 0.00 & 0.98 & 0.12 & 0.16 \\
\hline Greater than high school education & -0.08 & 0.25 & 0.00 & 0.97 \\
\hline Currently employed & -0.04 & 0.54 & -0.11 & 0.09 \\
\hline $\begin{array}{l}\text { Main event 1: direct event, assault, } \\
\quad \text { or intentional violence }\end{array}$ & 0.08 & 0.28 & 0.22 & 0.01 \\
\hline Main event 2: direct traumatic event & 0.40 & 0.05 & 0.45 & 0.04 \\
\hline $\begin{array}{l}\text { Main event 3: disappearance, death } \\
\text { or injury of loved ones }\end{array}$ & 0.27 & $<0.01$ & 0.24 & $<0.01$ \\
\hline R-squared & & 0.20 & & 0.19 \\
\hline Adjusted R-squared & & 0.17 & & 0.16 \\
\hline
\end{tabular}

* Referent group for age is 26-35-year olds.

**PTS score based on number of symptoms from DSM-IV diagnosis of PTSD, and mean score of self-perception and functioning scale.

experienced traumatic events were more likely to report PTS symptoms and suffer from poor general functioning. This association was robust to adjustment for covariates including gender and age. There was a dose-response relation between the burden of cumulative traumas and PTS symptoms such that persons reporting multiple traumatic events reported more PTS symptoms and worse functioning.
There is abundant evidence that there is a high prevalence of PTS symptoms in general populations who experience mass traumas soon after these events (Drozdek et al, 1997; Galea et al, 2003;). Dahl et al. (1998), working with displaced women in a refugee camp in Bosnia, found $47 \%$ to $71 \%$ experienced PTS symptoms shortly after experiencing trauma and dislocation. Ahern et al. (2004) conducted a study among ethnic Kosovars presenting to an emergency room, and again found a high prevalence of PTS symptoms in the general community. A recent review article of the PTS literature after mass traumas found that PTS symptoms decline as time passes after a traumatic exposure, but that the impact of the trauma on high-risk groups may endure (Neria et al, 2007). The Halabja data, by looking back 18 years, provide new evidence that PTS symptoms and poor general functioning may remain major problems in the civilian population, even decades after mass traumatic experiences.

There is growing evidence that cumulative exposure to traumatic events is associated with incrementally greater risk of PTS disorder. In Bosnia, Klaric et al. (2007) described the impact of repeated wartime trauma on women in Mostar, and found an association between the number of stressful events and postwar psychosocial dysfunction. In Sweden, Frans et al. (2005) interviewed 1824 randomly selected men and women, and found that PTS disorder was associated with multiple trauma experiences. The experience of persons in Halabja also suggests an association between cumulative traumatic event exposure and greater risk of PTS symptoms, and it supports the notion that this occurs across cultural boundaries.

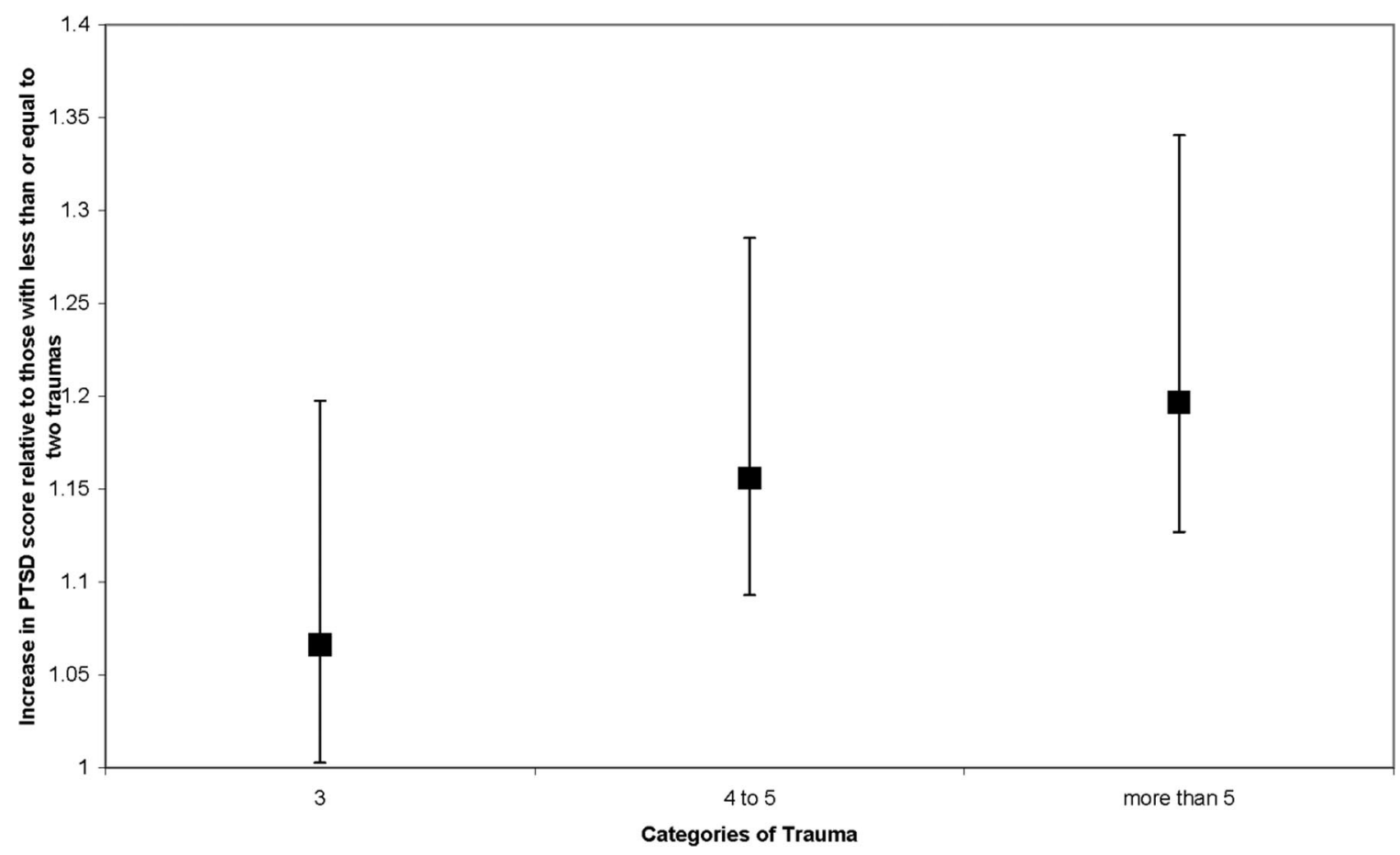

FIGURE 1. Relative increase in post-traumatic stress (PTS) score associated with greater exposure to traumatic events among residents of Halabja, Iraq. 
In studies conducted in postwar settings, female gender and older age are associated with more PTS symptoms (Farhood et al, 2006; Scholte et al, 2004). The data from Halabja are consistent with these results, with women and the elderly at increased risk demographically for PTS symptoms and poorer overall function.

There were several limitations to our study. Data regarding exposure to the attacks are retrospective, and rely on testimony about events that occurred 18 years ago. This increases the risk of recall bias, particularly in Halabja, where previous human rights abuses are still a politically charged topic (Worth, 2006). Because we determined exposure and outcomes simultaneously, we cannot establish causality (Kelsey et al, 1996; Rothman et al, 1998). In addition, we recruited a systematic sample of persons presenting to the emergency department and outpatient clinics. We adopted this approach because a random population-based sample was not feasible. It is possible that the persons who presented to the clinical sites of this study were more likely to have PTS symptoms and poor functioning than other civilians in the general population, which would suggest that our estimates here are overestimates.

Notwithstanding these limitations, our study provides data about the long-term challenges faced by a community that suffered notorious human rights violations, including a nonconventional weapons attack on civilians. Recent articles have suggested that the long-term impact of war on psychosocial and physical health is often overlooked by policy makers, despite the emerging evidence that traumatized populations remain disadvantaged on a number of economic and social fronts long after fighting has ceased (Galea and Wortman, 2006). More research is needed to determine the societal cost of human rights abuses and to identify groups of persons at increased risk of psychological dysfunction years after the fighting stops.

\section{ACKNOWLEDGMENTS}

The authors wish to thank the following people for providing technical assistance to this project: Rebeen Haidar BCS, Ako, MD, Ali Kurdistani, Shwan Kanan, MD, Hero, Aljaf, MD, Pershing Khan, Ali Sindi, MD, Christopher
Gessner, Joseph Bush, Andy Jagoda, MD, and Sigrid Hahn, MD, David Muller, MD.

\section{REFERENCES}

Ahern J, Galea S, Fernandez WG, Koci B, Waldman R, Vlahov D (2004) Gender, social support and posttraumatic stress in postwar Kosovo. J Nerv Ment Dis. 192:762-770.

Burns John F Hussein Cousin Sentenced to Die for Kurd Attacks. New York Times. June 25, 2007.

Dahl S, Mutapcic A, Schei B (1998) Traumatic events and predictive factors for posttraumatic symptoms in displaced Bosnian women in a war zone. J Trauma Stress. 11:137-145.

Drozdek B (1997) Follow-up study of concentration camp survivors from Bosnia-Herzegovina: three years later. J Nerv Ment Dis. 185:690-694.

Farhood Laila, Dimassi Hani, Lehtinen Tuija (2006) Exposure to war-related traumatic events, prevalence of PTSD and general psychiatric morbidity in a civilian population from southern Lebanon. J Transcult Nurs. 17:333.

Frans O, Rimmö PA, Aberg L, Fredrikson M (2005) Trauma exposure and post-traumatic stress disorder in the general population. Acta Psychiatr Scand. 111:291-299.

Galea S, Vlahov D, Resnick H, Ahern J, Susser E, Gold J, Bucuvalas M, Kilpatrick D (2003) Trends of probable post-traumatic stress disorder in New York City after the September 11 terrorist attacks. Am J Epidemiol. 158:514-524.

Galea S, Wortman K (2006) The population health argument against war. [commentary] World Psychiatry. 5:31-32.

Human Rights Watch (1991) Whatever Happened to the Iraqi Kurds? Available at: http://www.hrw.org/reports/1991/IRAQ913.htm\#6. Human Rights Watch (1993) The Anfal Campaign Against the Kurds. Available at: http://www.hrw.org/reports/1993/iraqanfal/.

Kelsey JL, Whittemore AS, Evans AS (Eds), (1996) Methods in Observational Epidemiology (2nd ed). Oxford, United Kingdom: Oxford University Press.

Klaric M, Klarić B, Stevanović A, Grković J, Jonovska S (2007) Psychological consequences of war trauma and postwar social stressors in women in Bosnia and Herzegovina. Croat Med J. 48:167-176.

Mollica RF, Caspi-Yavin Y, Bollini P, Truong T, Tor S, Lavelle J (1992) The Harvard Trauma Questionnaire. Validating a cross-cultural instrument for measuring torture, trauma and posttraumatic stress disorder in Indochinese refugees. J Nerv Ment Dis. 180:111-116.

Neria Y, Nandi A, Galea S (2007) Posttraumatic stress disorder following disasters: A systematic review. Psychol Med. In press.

Rothman KJ, Greenland S (Eds) (1998) Modern Epidemiology (2nd ed). Philadelphia, PA: Lippincott, Williams \& Wilkins.

Scholte Willem, Olff Miranda, Ventevogel Peter, de Vries Giel-Jan, Jansveld Eveline, Cardozo Barbara, Crawford Carol (2004) Mental health symptoms following war and repression in Eastern Afghanistan. JAMA. 292: $585-593$.

Worth Robert Kurds Destroy Monument in Rage at Leadership. New York Times. March 17, 2006. 